\title{
Movimentos INDíGENAS DO SÉCULO XX
}

\author{
Entrevista concedida por Claudia Zapata
}

a Sara Rojo e Graciela Ravetti

âmbito de pesquisa de Claudia Zapata (professora, pesquisadora e Coordenadora do Mestrado em Estudos Latino-Americanos da Universidade do Chile) é a história contemporânea da América Latina e, focalizando mais especificamente, os movimentos indígenas do século XX. Nesta entrevista, realizada em Santiago do Chile, em janeiro de 2008, assim como no artigo que publicamos neste número de Aletria, ela nos apresenta informações e reflexões novas sobre o tema.

Aletria - Qual a sua opinião em relação ao pensamento sobre a alteridade hoje?

Zapata - Em primeiro lugar, deve-se indicar a importância das reflexões teóricas sobre a alteridade e não porque sua existência seja algo novo, mas sim porque, hoje, amplos coletivos sociais, políticos e intelectuais se manifestam predispostos a reconhecê-la e valorizá-la em todos os campos onde estas alteridades se expressam. Ao mesmo tempo, existe uma amplitude enorme que obriga a circunscrever as idéias que aqui proponho, já que estas se restringem às sociedades indígenas americanas, durante o século XX. Esta amplitude, longe de ser um problema, aparece como uma possibilidade para enriquecer o debate e o intercâmbio entre disciplinas e áreas de estudos que se propõem a resgatar histórias protagonizadas pelos sujeitos que entendemos como depositários destas alteridades. A multiplicidade de experiências e sujeitos que abarca a idéia de alteridade provoca uma pergunta básica: alteridade com respeito a que e a quem? E vemos que o assunto tem a ver com o contraste que é possível estabelecer em relação àquele sujeito metropolitano insistentemente mencionado como masculino, branco e ocidental, insistência um pouco inoportuna, às vezes, mas que é real. Portanto, quando se fala de alteridade, por muito vaga que seja a afirmação, refere-se a tudo aquilo que se distancia de uma configuração histórica particular que foi instalada como a única válida. Dentro desta amplitude, meu trabalho se situa num tipo de alteridade bem específica, uma de tipo político-cultural que, no caso indígena americano e, em geral, das ex-colônias, foi rotulada mais comumente como "outridade".

Ainda que a outridade ou alteridade nunca tenha sido um tema irrelevante, a diferença está marcada por como essa alteridade é entendida e abordada. Portanto, uma característica de nossa época que me parece relevante é que existe uma sensibilidade crescente que valoriza trajetórias culturais e históricas que não só são distintas, mas que, ainda por cima, foram inferiorizadas num jogo de poder no qual se constitui a superioridade branco/ocidental/ 
capitalista, questão que se encontra na base dos processos de expropriação e pobreza que afetam as sociedades indígenas, constituindo uma desvantagem que tem sua origem (e solução) neste conflito histórico.

Agora bem, transcorrido o tempo e no auge do desenvolvimento dos movimentos indígenas que, diferente daqueles que surgiram em outros períodos da história republicana, têm como principal bandeira de luta a reivindicação destas diferenças, vale a pena interrogar-se sobre as possibilidades que abrem e fecham os distintos discursos sobre alteridade ou outridade. No meu caso, o resultado deste exercício é uma reflexão crítica que encontrou um valioso apoio em autores que souberam identificar os riscos que contêm algumas exaltações de outridade. Refiro-me ao autor palestino Edward Said, à antropóloga argentina Claudia Briones e ao crítico britânico Terry Eagleton, para assinalar meus principais referentes teóricos neste tema. Vejo nestes autores - a quem ninguém poderia acusar de eurocentristas - uma linha de argumentação que não é a predominante neste tema, que consiste, basicamente, em questionar todo tipo de essencialismo cultural, incluindo o que contêm alguns discursos que se propõem a criticar o essencialismo eurocêntrico com outro essencialismo que se refere a um mundo não ocidental difuso, mas melhor. No que diz respeito aos discursos contemporâneos sobre as sociedades indígenas (provenientes de distintas disciplinas), optei por lê-los a partir de um questionamento básico: qual é o tipo de outridade que se exalta? E as respostas são diferentes; estão além da vontade inicial de solidarizar-se com a história escandalosa de atropelos que a estes povos lhes coube viver. Uma posição freqüente, e que conta com muitos adeptos, é imaginar os indígenas de hoje como uma continuidade cultural relacionada com os indígenas de ontem (aqueles do período republicano inicial, do colonial e, inclusive, do pré-hispânico, quando eles nem sequer existiam como "índios"), como uma sociedade eminentemente ritual cuja sociabilidade transcorre nos vínculos de parentesco, e que tem uma relação estreita e espiritual com a natureza, vale dizer, com tudo aquilo que cabe sob o rótulo de "tradicional". O problema destas descrições origina-se na sua falta de historicidade, pois seu ponto de partida é uma suposição prévia de como são (e deveriam ser) os indígenas, colocando num segundo plano o vínculo com a sociedade na qual estão inseridos (neste caso, a chilena) e até mesmo o fato colonial. Portanto, e esta é uma das questões que discuto na pesquisa que atualmente estou desenvolvendo, a "diferença" ou "outridade" indígena é real, mas não se restringe à cultura; está cruzada com essa história imperial, que funda a categoria do que se considera propriamente de índio/indígena e o conflito que a rodeia até hoje. Este cruzamento entre cultura e história é o que me permite entender essa diferença em termos variáveis, cuja forma vai depender da relação particular que se configura entre os indígenas e a sociedade chilena como um todo.

O risco principal da posição que acabo de questionar é que a idéia do indígena que dela se desprende (bastante romântica) impõe parâmetros de 
autenticidade que operam com maior ou menor grau, excluindo sujeitos que não se encaixam nessas descrições. Isto explica a atenção tardia que se dispensou aos indígenas urbanos ou aos pressupostos que sustentam as pesquisas que os abordam, e que falam de indígenas que habitam um espaço "alheio", sem entender que as cidades são cenários étnicos, pelo menos desde a metade do século XX. Mais problemáticos ainda são aqueles sujeitos indígenas que se desenvolvem na sociedade chilena como um todo de maneira permanente e de acordo com seus códigos, entre eles, os profissionais e intelectuais, evitados e pouco estudados precisamente porque não são depositários daquilo que se supõe que seria autenticamente indígena. Minha pesquisa sobre os intelectuais indígenas que se formaram na educação superior se deteve nesse ponto, responsabilizando-se do motivo pelo qual acaba sendo pouco "digerível" a conjunção dos conceitos aparentemente contraditórios: ser "intelectual" e "indígena". Em conclusão, parece-me que o problema é que algumas reivindicações da outridade costumam ser essencialistas e autoritárias com respeito aos sujeitos reais que, na atualidade, compõem as sociedades indígenas heterogêneas, o que impede medir com justiça sua historicidade.

Aletria - Você acredita que tal teorização foi produtiva durante as últimas décadas do século XX?

Zapata - A possibilidade de discutir este tipo de questões e, sobretudo, os projetos políticos que dão lugar a uma ou outra posição, faz com que o estudo do tema seja produtivo, mas, além disso, deve ser entendido como parte de um contexto maior de crise, no qual estas reflexões aparecem como respostas que buscam construir novos sentidos. Refiro-me ao fim da Guerra Fria, à crise da esquerda e ao protagonismo de sujeitos que deram vida a potentes movimentos sociais fundados em identidades culturais e genérico-sexuais, entre outras. A reivindicação dessas práticas, que já não se associam (unicamente) ao problema da classe, constitui para um setor importante dos intelectuais latinoamericanos uma forma de militância político-teórica na qual se busca resolver um dilema: como ser de esquerda, depois da derrota?

Tanto essa crise quanto o papel determinante que tiveram os chamados novos movimentos sociais desde os anos oitenta do século passado, erigiram os movimentos indígenas como referentes para vários autores e cientistas sociais que reformularam seus ideais libertários, deslocando a crítica da burguesia e do capitalismo para a modernidade e a cultura ocidental. Nesse propósito, as sociedades indígenas são destacadas pelo que se manifesta fora delas em relação a esse Ocidente moderno que se procura combater no âmbito cultural, teórico e epistemológico, posição que aparece como um atributo desejável por si. Há, inclusive, aqueles autores que não ocultaram seu desejo de substituir toda sua formação acadêmica ocidental pela chamada epistemologia indígena (o que se escutou nos últimos tempos de Walter Mignolo), projeto que parte de uma distância insuperável entre indígenas e não indígenas. Vários são os autores latino-americanos que sustentam seus trabalhos nessa dicotomia, entre 
os quais todos parecem concordar - certamente, com matizes - que os indígenas constituem uma alternativa em relação à política tradicional, ao conhecimento científico, ao capitalismo e à episteme moderna (poderiam ser mencionados, entre outros, Enrique Dussel com El encubrimiento del indio: 1492, John Beverley com Subalternidad y representación, Silvia Rivera Cusicanqui com "La raíz: colonizadores y colonizados”, e, mais recentemente, Javier Sanjinés com El espejismo del mestizaje).

Portanto, além da distância que, no aspecto pessoal, tenho em relação a esses enfoques relacionados à outridade, resgato esse debate como uma forma de responder a uma crise cultural que se supunha que fosse anular projetos intelectuais e político-críticos que se propõem a transformar a sociedade.

\section{Aletria - A partir da reflexão produzida sobre esse tema, quais caminhos podemos seguir atualmente?}

Zapata - Neste ponto, prefiro responder a partir do meu tema de especialização, por ser o que me parece mais familiar, mas também pela atual contingência política do Chile. Atualmente, acredito que estamos presenciando um desenvolvimento dos movimentos indígenas que permitem discutir sobre a relação entre a reflexão teórica e o devir político, isso porque o predomínio da posição romântica que descrevi nas perguntas anteriores (que, ademais, não é nova na história da modernidade, pois a possibilidade do externo, paralelo e distinto fez parte da crítica do projeto moderno desde seus inícios) entra hoje em colisão com a real politik dos movimentos indígenas que monopolizam a cena latino-americana. Assim, mais que indígenas que se refugiam nas práticas tradicionais de liderança e organização, vemos que as organizações étnicas fizeram com que as vias e procedimentos, que não têm muita relação com essa outridade que os vincula com o espaço rural, a comunidade e a cosmovisão radicalmente "outra", fossem suas. Isso trouxe como resultado a existência de parlamentares, ministros e, inclusive, um presidente indígena.

Essa colisão abre duas alternativas: insistir nessa ficção cultural que não condiz com o desenvolvimento cultural e histórico dos povos indígenas (o que não quer dizer que a diferença cultural não exista, como expliquei anteriormente) ou supor, em outro extremo do argumento, que esses sujeitos não são suficientemente "puros" por não cumprirem com as características daquilo que nós consideramos que devem ser os índios. Novamente, é um problema de poder bastante complexo e dialético, como pode ser apreciado nos próprios discursos identitários dos indígenas que militam nesses movimentos, que, em relação à sociedade chilena como um todo e, especificamente, a esses discursos, assumem a importância da outridade cultural assim entendida, questão que derivou em processos identitários muito interessantes de retorno e busca.

A questão é, em minha opinião, entender que a categoria de "índio" é política, e não cultural como se costuma pensar, ainda que o elemento cultural seja um componente relevante, utilizado nos mecanismos de inferiorização 
desses coletivos. Portanto, todo discurso sobre os índios careceu e carece de neutralidade, pois, ao contrário, eles contêm uma potente carga ideológica, da mesma forma que os discursos formulados pelos próprios indígenas em distintos períodos. Creio que este ponto de partida abre o caminho para entendê-los como interlocutores políticos com quem se pode e se deve dialogar em igualdade de condições.

A

Tradução de Marcos Antônio Alexandre 